\title{
Effectiveness of newborn pulse oximetry screening for the identification of critical congenital heart disease in a tertiary care hospital in Sri Lanka
}

\author{
*N C Gamhewage ${ }^{1}$, K S Y Perera ${ }^{2}$, Medha Weerasekera ${ }^{3}$ \\ Sri Lanka Journal of Child Health 2021; 50(4): 699-703 \\ DOI: http://doi.org/10.4038/sljch.v50i4.9890
}

\begin{abstract}
Background: Critical congenital heart disease (CCHD) constitutes a spectrum of different heart anomalies needing intervention early in life for survival. Pulse oximetry screening (POS) claims to have a sensitivity of $60 \%$, specificity of $99.95 \%$, positive predictive value (PPV) of $75 \%$ and a negative predictive value (NPV) of $99.98 \%$ in detecting CCHD.
\end{abstract}

Objectives: To assess the effectiveness of POS in identifying CCHD in a tertiary care neonatal unit in Sri Lanka.

Method: A prospective descriptive study was carried out at Sri Jayewardenepura General Hospital (SJGH) from October 2017 to March 2020 including all healthy newborns delivered at SJGH. Babies with a prenatal diagnosis of CHD and those who needed admission to neonatal unit before POS was performed were excluded. Recruited babies underwent POS after 24 hours, but before 48 hours of life, in addition to routine newborn examination.

Results: There were 8964 live births during the study period. POS was carried out in 8718 babies and was positive in 19 babies; 18 babies had CHD confirmed by echocardiogram, out of which 14 had CCHD. Hence, the incidence of CCHD, identified by POS was 1.56 per 1000 live births. Furthermore, POS demonstrated a PPV of $73.7 \%$, and a false positive rate of $0.06 \%$.

\section{${ }^{1}$ Lecturer in Paediatrics, University of Sri Jayewardenepura, Sri Lanka, ${ }^{2}$ Medical Officer, Neonatal Intensive Care Unit, Sri Jayewardenepura General Hospital, Sri Lanka, ${ }^{3}$ Consultant Neonatologist, Neonatal Intensive Care Unit, Sri Jayewardenepura General Hospital, Sri Lanka *Correspondence: nimeshagamhewage@sjp.ac.lk \\ (iD) https://orcid.org/0000-0001-5129-4158}

(Received on 03 November 2020: Accepted after revision on 18 January 2021)

The authors declare that there are no conflicts of interest.

Personal funding was used for the project.

Open Access Article published under the Creative

Commons Attribution CC-BY@C (i) License
Conclusions: In this tertiary care neonatal unit in Sri Lanka POS was detected CCHD in 1.56 per 1000 live births with a PPV of $73.7 \%$, and a false positive rate of $0.06 \%$.

(Key words: Pulse oximetry screening, Newborn, Critical congenital heart disease, Developing country, Diagnosis)

\section{Introduction}

Critical congenital heart disease (CCHD) constitutes a spectrum of different heart anomalies needing intervention early in life for survival ${ }^{1}$. CCHD accounts for more than $20 \%$ of perinatal deaths due to congenital malformations and about $50 \%$ of early childhood deaths associated with congenital malformations are known be due to congenital heart disease (CHD) ${ }^{2}$. Missed or late diagnosis of CCHD can lead to serious adverse effects including death, and a Californian study demonstrated that as many as 30 infants die annually due to either missed or delay in identification of $\mathrm{CCHD}^{3}$. Most of the deaths were due to hypoplastic left heart syndrome and coarctation of aorta and the median age at death was below 2 weeks ${ }^{3}$, highlighting the importance of screening for CCHD.

Until recently, especially in developing countries, the hallmark of diagnosing CHD was clinical examination, which included auscultating the praecordium and palpating femoral pulses. However, it is known that clinical examination alone is not sufficient to identify all forms of $\mathrm{CCHD}^{4}$. This is partly due to increased pulmonary pressure during the early newborn period preventing significant left to right shunts. Furthermore, presentation of some CCHD is delayed until the duct is closed. In many instances, antenatal diagnosis of CHD is possible, with anomaly scan. However, studies claim that up to $40 \%$ of CCHD could be missed in antenatal assessments, even in developed countries ${ }^{5}$. Furthermore, some of the CHD could continue to develop and evolve in the fetus during the latter part of pregnancy ${ }^{2}$.

Since 1995, a multitude of studies have been conducted to assess the efficacy of pulse oximetry screening (POS) to detect $\mathrm{CCHD}^{1,6,7,8,9}$. POS claims to have $60 \%$ sensitivity, $99.95 \%$ specificity, $75 \%$ positive predictive value (PPV) and $99.98 \%$ 
negative predictive value $(\mathrm{NPV})^{9}$. Interestingly, a systematic review noted that POS can identify 5 out of 6 babies with CCHD. Furthermore, the false positive rate is $0.06 \%$ and $0.42 \%$, when POS is done after 24 hours of age and before 2 hours of age, respectively ${ }^{10}$. Therefore, POS has gained popularity across the world for detection of CCHD.

According to the Family Health Bureau (FHB), in 2019 the neonatal mortality rate (NMR) in Sri Lanka was reported to be 7 per 1000 live births ${ }^{11}$. Of the neonatal deaths $54.5 \%$ were due to congenital anomalies $^{12}$. In one of the previous studies conducted in our unit, the incidence of CHD was 125 per 10,000 live births ${ }^{13}$. We described an incidence of 2.95 and 30.52 per 10,000 live births for lethal heart disease and clinically significant heart disease respectively ${ }^{13}$. In Sri Lanka, anomaly scans are not routinely performed in all pregnancies and hence there is a great likelihood of missing CCHD in our setup. This signifies the importance of POS of neonates before discharge, with an aim to detect CCHD.

\section{Objectives}

To assess the effectiveness of POS in identifying CCHD in a tertiary care neonatal unit in Sri Lanka.

\section{Method}

This is a prospective descriptive study carried out at Sri Jayewardenepura General Hospital (SJGH) over a period of 30 months. All term newborns (born at 37-40 weeks of gestation) delivered at SJGH were included in the study. Parents were approached after the birth of the baby. Exclusion criteria were babies with antenatal diagnosis of CHD and those who were admitted before POS was carried out. Recruited babies underwent POS after 24 hours, but before 48 hours of life, along with routine newborn examination.

As per guideline issued by $\mathrm{FHB}^{14}$ in 2017 , positive screening was considered as pre-ductal saturation below $95 \%$ or more than $3 \%$ difference between preductal and post-ductal saturations. All the babies who had a positive screening were evaluated with an echocardiogram by the Paediatric Cardiologist. The period of gestation, clinical examination findings, gender and type of abnormality were recorded.

Ethical issues: Particulars of patients collected during the study were kept confidential. The study was approved by the Ethics Review Committee of SJGH (No. SJGH/20/ERC/037). Informed written consent was obtained from the parents of all babies participating in the study.

\section{Results}

There were 8964 live births during the study period of which $50.6 \%$ were boys. Study population consisted of term babies, born at 37 to 40 weeks of gestation. Birth weights were between $2000 \mathrm{~g}$ to $4000 \mathrm{~g}$. POS was carried out in 8718 babies and was positive in 19 babies; 246 babies were excluded from the study as they were admitted to the neonatal intensive care unit (NICU) before POS was performed (Table 1). There were no babies with antenatal diagnosis of CHD

Table 1: Diagnosis of neonates admitted to unit before pulse oximetry screening was performed

\begin{tabular}{|l|c|}
\hline \multicolumn{1}{|c|}{ Diagnosis } & Number of babies \\
\hline Congenital pneumonia & 46 \\
\hline Transient tachypnoea of newborn & 57 \\
\hline Poor adaptation at birth/ Hypoxic ischaemic encephalopathy & 13 \\
\hline Congenital abnormalities needing surgical intervention & 17 \\
\hline Meconium aspiration syndrome & 08 \\
\hline Respiratory distress syndrome & 5 \\
\hline Congenital heart disease & 2 \\
\hline Observed for respiratory distress & 20 \\
\hline Sepsis & 44 \\
\hline Persistent pulmonary hypertension of the newborn & 1 \\
\hline Baby was admitted due to maternal complications & 33 \\
\hline
\end{tabular}

Among the babies included in the study, 18 had CHD confirmed by echocardiogram, out of which 14 had CCHD (Table 2). Therefore, the incidence of CCHD detected via POS in our population, as per inclusion criteria is 1.56 per 1000 live births. In our setting, POS has a positive predictive value of $73.7 \%$, with a false positive rate of $0.06 \%$. 
Table 2: Types of critical congenital heart disease detected by pulse oximetry screening

\begin{tabular}{|l|c|}
\hline \multicolumn{1}{|c|}{ Type of critical congenital heart disease } & Number of babies \\
\hline Total anomalous pulmonary venous drainage & 03 \\
\hline Pulmonary atresia & 03 \\
\hline Hypoplastic left heart syndrome & 04 \\
\hline Atrio-ventricular canal defect & 01 \\
\hline Truncus arteriosus & 01 \\
\hline Tetralogy of Fallot & 01 \\
\hline Transposition of great arteries & 01 \\
\hline
\end{tabular}

Four babies had non-critical CHD, including atrial septal defect (ASD) and patent ductus arteriosus (PDA). One baby had a normal echocardiogram. Of note, only 2 babies had cyanosis on admission, and 3 babies had a murmur. Altogether, only 3 babies were symptomatic prior to diagnosis of CHD.
Among the babies with CCHD, 4 were lost to follow up. It is important to note that 7 babies could survive the neonatal period but of them 4 were lost to follow up. The outcome of the babies with CCHD is shown in table 3 .

Table 3: Outcome of babies with critical congenital heart disease

\begin{tabular}{|l|c|c|c|c|}
\hline \multicolumn{1}{|c|}{ Type of cardiac anomaly } & Died & Survived & $\begin{array}{c}\text { Survived neonatal } \\
\text { period but lost to } \\
\text { follow up }\end{array}$ & $\begin{array}{c}\text { Total } \\
\text { number of } \\
\text { babies }\end{array}$ \\
\hline Total anomalous pulmonary venous drainage & 02 & 01 & & 03 \\
\hline Pulmonary atresia & & 01 & 02 & 03 \\
\hline Hypoplastic left heart syndrome & 03 & & 01 & 04 \\
\hline Atrio-ventricular canal defect & & & & 01 \\
\hline Truncus arteriosus & 01 & & & 01 \\
\hline Tetralogy of Fallot & 01 & & & 01 \\
\hline Transposition of great arteries & & 01 & & 01 \\
\hline
\end{tabular}

Among the babies, who were excluded from the study, there were 2 babies with CCHD. These babies were admitted to the NICU soon after birth due to significant cyanosis associated with murmur and need for respiratory support. Therefore, in these 2 babies, presence of significant CHD was apparent prior to POS. They were subsequently diagnosed as having supra-cardiac TAPVD and dysplastic Ebsteinoid tricuspid valves with duct dependent circulation. Finally, during the 30 months of study period, there was a total of 16 babies with CCHD, giving an incidence of 1.79 per 1000 live births, in our institution.

\section{Discussion}

This is the first Sri Lankan study evaluating the effectiveness of neonatal POS in identifying CCHD. We have screened a large population of term babies using POS and have demonstrated its efficacy as well as feasibility. CCHD has a reported incidence of 1.6 to 1.7 per 1000 births $^{15,16}$, which is comparable to our findings. Furthermore, positive predictive value and false positive rates are comparable to statistics reported in other studies ${ }^{9,10}$. This relates to the fact that we have performed POS after 24 hours of life, using standard guidelines.

As all neonates with positive POS were subjected to echocardiography by a Paediatric Cardiologist, babies were taken in for emergency surgical procedures where indicated, while others were planned for follow up till elective surgery or palliative/comfort care if unsuitable for surgical correction. In all cases, parents were counselled by the Cardiologist at the time of echocardiogram confirmation and by the neonatology team with regard to further care till discharge, transfer or demise in comfort care. This we realised is a very important step in quality of care in a group of neonates who would have been discharged as "well neonates" in a set up without POS. It is important to understand, in the absence of POS, these neonates would have been re-admitted in critical status and would perish without the correct diagnosis.

We could not follow up all the babies discharged from the hospital with a negative screening test. Therefore, there is a possibility that we could have missed newborns with CCHD, which is a limitation in our study. As routine anomaly scans are not performed in all pregnant mothers, sensitivity of POS in our population could potentially be higher than described in developed countries.

POS is a non-invasive and simple procedure which can detect CCHD in neonates effectively. It also of value in confirming the diagnosis in a group of neonates who will otherwise be in the grey areas of diagnosis related to morbidity and mortality. 
Further studies need to be conducted in Sri Lanka, to assess its sensitivity and specificity

\section{Conclusions}

In this tertiary care neonatal unit in Sri Lanka POS detected CCHD in 1.56 per 1000 live births with a PPV of $73.7 \%$, and a false positive rate of $0.06 \%$.

\section{References}

1. Riede FT, Wörner C, Dähnert I, Möckel A, Kostelka M, Schneider P. Effectiveness of neonatal pulse oximetry screening for detection of critical congenital heart disease in daily clinical routine: results from a prospective multicentre study. European Journal of Pediatrics 2010; 169(8): 975-81. https://doi.org/10.1007/s00431-010-11604 PMid: 20195633 PMCid: PMC2890074

2. Yagel S, Weissman A, Rotstein Z, Manor M, Hegesh J, Anteby E, et al. Congenital heart defects, Natural course and in utero development. Circulation 1997; 96 (2): 550-5.

https://doi.org/10.1161/01.cir.96.2.550

PMid: 9244224

3. Chang RR, Gurvitz M, Rodriguez S. Missed diagnosis of critical congenital heart disease. Archives of Pediatrics and Adolescent Medicine 2008; 162(10): 96974.

https://doi.org/10.1001/archpedi.162.10.96 9

PMid: 18838650

4. Ainsworth S, Wyllie JP, Wren C. Prevalence and clinical significance of cardiac murmurs in neonates. Archives of Disease in Childhood: Fetal and Neonatal Edition 2009; 80(1): F43-F45.

https://doi.org/10.1136/fn.80.1.f43

PMid: 10325811 PMCid: PMC1720873

5. Hill GD, Block JR, Tanem JB, Frommelt MA. Disparities in the prenatal detection of critical congenital heart disease. Prenatal Diagnosis 2015; 35(9): 859-63. https://doi.org/10.1002/pd.4622 PMid: 25989740 PMCid: PMC4558244

6. Arlettaz R, Bauschatz AS, Mönkhoff M, Essers B, Bauersfeld U. The contribution of pulse oximetry to the early detection of congenital heart disease in newborns. European Journal of Pediatrics 2006; 165(2): 94-8. https://doi.org/10.1007/s00431-005-0006$\mathrm{y}$

PMid: 16211399

7. Bakr AF, Habib HS. Combining pulse oximetry and clinical examination in screening for congenital heart disease. Pediatric Cardiology 2005; 26(6): 832-835.

https://doi.org/10.1007/s00246-005-09819

PMid: 16088415

8. Hoke TR, Donohue PK, Bawa PK, et al. Oxygen saturation as a screening test for critical congenital heart disease: a preliminary study. Pediatric Cardiology 2002; 23(4): 403-9. https://doi.org/10.1007/s00246-002-14828

PMid: 12170356

9. Koppel RI, Druschel CM, Carter T, Goldberg BE, Mehta PN, Talwar R, et al. Effectiveness of pulse oximetry screening for congenital heart disease in asymptomatic newborns. Pediatrics 2003; 111(3): 451-5. https://doi.org/10.1542/peds.111.3.451. PMid: 12612220

10. Plana MN, Zamora J, Suresh g, FernandezPineda 1, Thangaratinam S, et al. Pulse oximetry screening for critical congenital heart defects. Cochrane Database of Systemic Reviews 2018; 1(3): CD011912. https://doi.org/10.1002/14651858.CD0119 12.pub2

PMid: 29494750 PMCid: PMC6494396

11. Family Health Bureau [homepage on the Internet] Available from:

https://www.fhb.health.gov.lk/index.php/t a/statistics

12. Arambepola C, Jayaratne K, Rowel D, Walpita YN, Pieris D. Perinatal Death Surveillance in Sri Lanka 2014-2017. Maternal \& Child Morbidity and Mortality Surveillance Unit, Family Health Bureau Ministry of Health, Sri Lanka. Sponsored by UNICEF Country Office Sri Lanka

13. Perera KSY, Gamhewage NC, Weerasekera M. Prospective study on incidence and pattern of congenital abnormalities in a tertiary care hospital in Sri Lanka. Sri Lanka Journal of Child Health 2019; 48(4): 321-5. http://dx.doi.org/10.4038/sljch.v48i4.8826 
14. Family Health Bureau [homepage on the Internet]. Available from:

https://www.fhb.health.gov.lk/index.php/t a/resources/guidelines

15. Zhang X, Sun Y, Zhu J, Zhu Y, Qiu L. Epidemiology, prenatal diagnosis, and neonatal outcomes of congenital heart defects in eastern China: a hospital-based multicenter study. BMC Pediatrics 2020; 20: 416.

https://doi.org/10.1186/s12887-020023134

PMid: 32878605 PMCid: PMC7466801
16. Oster ME, Lee KA, Honein MA, RiehleColarusso T, Shin M, Correa A. Temporal trends in survival among infants with critical congenital heart defects. Pediatrics 2013; 131(5):e1502-8.

https://doi.org/10.1542/peds.2012-3435

PMid: 23610203 PMCid: PMC4471949 